\title{
$\Omega$
}

D

'University of Medicine and Pharmacy "Grigore T Popa”, lasi, Romania. ${ }^{2}$ Dept of Pneumology and Allergology, State University of Medicine and Pharmacy "Nicolae

Testemitanu", Chisinau, Republic of Moldova

\section{Pulmonary rehabilitation: course report}

\section{Course organisers}

I. Vogiatzis, N. Koulouris, M.A. Spruit, Thierry Troosters

\section{Faculty}

C. Chrysohoou, E.M. Clini, F.M.E. Franssen, P. Laveneziana, Z. Louvaris, C.M. Nolan, M. Panagiotou, F. Pitta, C. Rochester, S.J. Singh, S. Zakynthinos

\section{Introduction}

The ERS course on pulmonary rehabilitation was held at the 1st Dept of Respiratory Medicine, and the Biomedical Research Foundation, Athens Academy, Athens, Greece, from April 6 to 8, 2017.

\section{Laura Ciobanu, Romania, a participant}

Courses in pulmonary rehabilitation have evolved in the last decade. More theoretical and practical issues, and more participants (71 in total) from more countries than ever gathered in Athens for the 3-day ERS school course in pulmonary rehabilitation. Numerous studies have proven the physiological, symptom-reducing, psychological and health economic benefits of pulmonary rehabilitation for chronic respiratory patients. There being no more need to know why, participants wanted to know how, when and how else to administer pulmonary rehabilitation when confronting with complex cases and multiple limitations. Pulmonary rehabilitation is unfortunately underused and frequently inaccessible to the patients; therefore, the general aim is to make it more accessible, affordable and acceptable everywhere around.

The pillars of the pulmonary rehabilitation community were there, important names that have built the pulmonary rehabilitation concept and guidelines, as well as enthusiastic users and new beginners in the field. This course would not have happened without the generous and active contribution of the organisers, including I. Vogiatzis, who was always smiling and willing to help, together with N. Koulouris, M.A. Spruit and T. Troosters, supported by many dedicated colleagues.

Mornings were busy with lectures: two sessions per day. The first two sessions were about outpatients, inpatients and home telerehabilitation, and strategies to assess and promote daily physical activity; they were chaired by T Troosters and E.M. Clini, respectively. The next
Cite as: Ciobanu L, Munteanu O. Pulmonary rehabilitation: course report. Breathe 2017; 13: 275-277. 
two sessions held on the second day were about assessment of efficacy of pulmonary rehabilitation, and cardiovascular, lung and peripheral muscle function assessment, chaired by I. Vogiatzis and P. Laveneziana, respectively. The last two sessions were held on the third morning, debating adjuncts to exercise training and pulmonary rehabilitation in non-COPD respiratory diseases, with $C$. Nolan and F.M.E. Franssen, respectively, as chairs. The lectures were followed by question-and-answer breaks, some of which has to be stopped due to limited time and overenthusiasm. Microphones were everywhere in the auditorium, attached to the chairs, so asking questions was easy and accessible.

Moreover, six workshops were available on two afternoons for all participants, divided into four groups. Throughout the workshops, we had the possibility to see several investigations aiming at extensive cardiac, lung and muscle assessment of the patients prior to receiving pulmonary rehabilitation. In these sessions, some of us became volunteers and the rest had the possibility to talk to the specialists, to raise questions, to clear up points of confusion and to see what the actual standard is. Physical training was illustrated by a real session with patients and devices currently in use. Very useful issues, treated both theoretically and practically, were patient activation, telecoaching and telerehabilitation. Workshops were really challenging for the organisers as every participant wanted to ask, know and better understand practical issues. We spoke a lot with the faculty and to each other; the meeting was very interactive.

On the third afternoon, a practical session was held with three lectures aiming at transcending the classical borders of pulmonary rehabilitation towards cardiac rehabilitation, and finding new methods to increase programme access and capacity. I. Vogiatzis was very proud of a special session on case reports held late on the third afternoon, at the end of the course. It was a new and successful activity proposed by the organisers that allowed seven participants to present their experience in the field and to formulate some educational messages to take home. Diversity was the main strength of this session, and participants were very keen to listen and ask questions. It was active, pleasant and different to see what pulmonary rehabilitation looks like in Australia, the Netherlands, Ireland, the UK and Romania.

As a novelty, we had to face the reality that, during professional events as courses or conferences, we are much less active. To prove it, we all received a pedometer to wear for $24 \mathrm{~h}$ and, thereafter, we have been provided with a personal physical activity and sleep movements report. And yes, we really become almost sedentary during these all-day meetings.

This course on pulmonary rehabilitation did not sort out all of the problems in the field but proposed where to start and emphasised the need to find new implementation strategies. I identified some new directions: an increased interest in combined cardiopulmonary rehabilitation, telecoaching, telerehabilitation and home pulmonary rehabilitation, and for using pulmonary rehabilitation in non-COPD patients and intensive care units. It was clearly emphasised that, besides our aims, we should take into consideration the patients' aims, which can be much more simple and practical than doctors'. In my opinion, if patients are dropping out of pulmonary rehabilitation courses in large numbers, wouldn't it be the perfect time to look for a less complicated, exhausting and unappealing programme design? We might perhaps use what makes people happy and keeps them motivated, like singing, dancing and creative play.

In Athens, the ancient city of old temples, forgotten gods and orange trees in bloom, our knowledge of pulmonary rehabilitation has flowered.

\section{Oxana Munteanu, Republic of Moldova, a participant}

Despite the fact that pulmonary rehabilitation is a core component of the management of a patient with chronic lung disease, not all patients across Europe have access to this type of service. Currently, including in my country, there is limited availability of pulmonary rehabilitation programmes. The recent ERS course in Athens brought together clinicians and academia to discuss and learn about recent advances in pulmonary rehabilitation.

Under conditions of limited financial resources, for many countries, telerehabilitation could be of real help in increasing patients' access to pulmonary rehabilitation. During the course, that point was raised by T. Troosters and I. Vogiatzis, who presented the cost effectiveness of different rehabilitation therapies, and highlighted the current evidence for telecoaching and telerehabilitation, as well as their applicability and availability for patients with airway diseases. Despite some limitations (very old patients with no experience with technology), the published telerehabilitation studies showed a reduction in hospital admissions and emergency department visits, and telerehabilitation encourages the patients to become more involved in the management of their own condition.

Emphasising the feasibility and effectiveness of the peripheral muscle training in hospitalised COPD patients, E.M. Clini presented data that show that the patients who started a rehabilitation course early during acute exacerbations have better health status and exercise capacity.

Supporting exercise training for idiopathic pulmonary fibrosis, C.M. Nolan described, in a very easy and comprehensive manner, the current evidence and shared her experience on the efficacy of a pulmonary rehabilitation programme in these patients. 
Presenting the systematic review data on the uses and measurement properties of the incremental shuttle walk test and endurance shuttle walk test in adults with chronic respiratory disease, S.J. Singh shared her experience and outlined the most critical aspect of these tests in a manner that was comprehensible even for persons with no previous experience, as I was.

The faculty's talks were complemented by the most interesting and enjoyable part of the course: the workshops. These catalysed all of us for interesting discussion and even debates. I was particularly impressed by the cardioimpedance and cardiopulmonary exercise testing workshop, for which I want to express my gratitude to P. Laveneziana, who provided an outstanding lecture and practical training.

During the course, all of us benefited from a very dedicated faculty that has shown willingness for individual consultative assistance and did not hesitate to offer any help during, and even after, the course by sharing their experience. All of us, trainers and mentees, enjoyed the guided tour organised by the ERS through the streets of Athens that hold a rich history, combined with the spirit of exciting discussions, friendship and new collaborations.

I feel fortunate to have attended this excellent course and to share the knowledge with my peers. This course offered me the opportunity to discuss with the experts and to gain the most updated messages on why, how and when rehabilitation

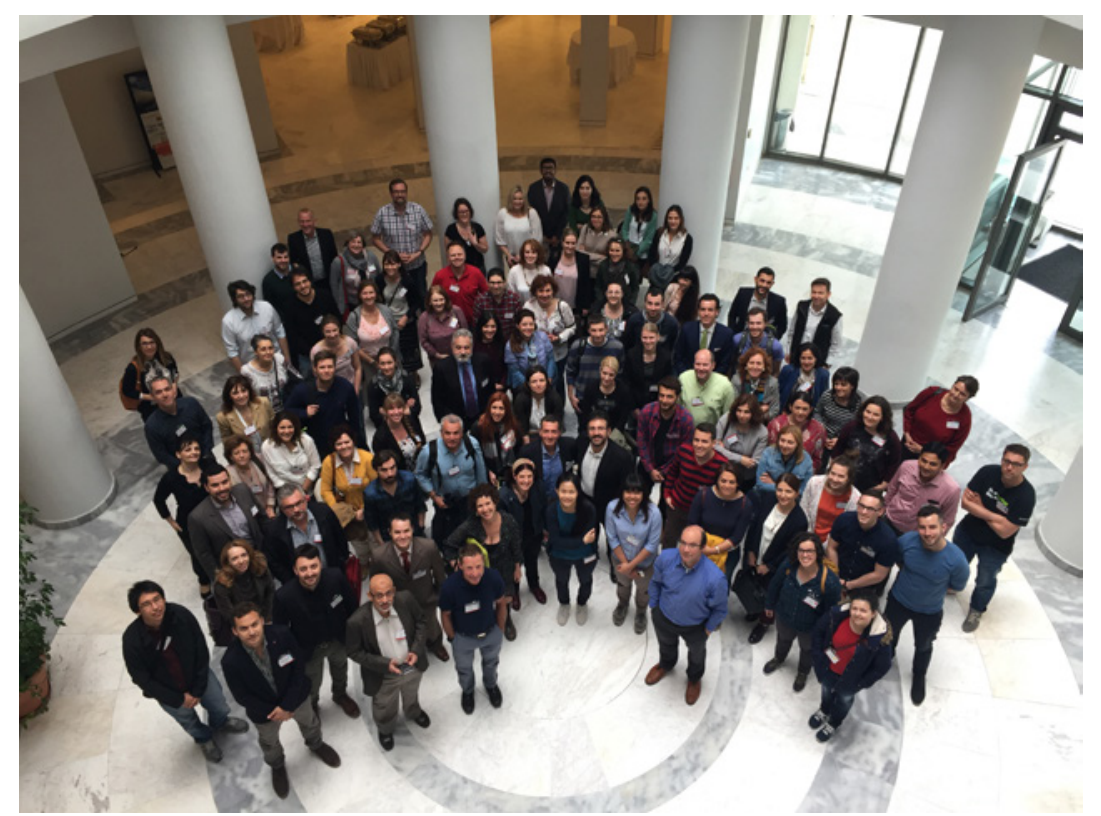

treatment should be delivered. I am sure that, being back home, I will get involved in the acceleration of the implementation of the pulmonary rehabilitation programmes and national training curriculum in my country. I thank the ERS, the faculty and all the participants for an insightful programme and an inspirational event.

\section{Conflict of interest}

None declared. 